\title{
Using phage Lytic Enzymes to Control Pathogenic Bacteria Vincent A Fischetti*
}

\author{
Address: Rockefeller University, New York, NY 10021, USA \\ Email: Vincent A Fischetti* - vaf@mail.rockefeller.edu \\ * Corresponding author
}

from Biotechnology and Biomaterials to Reduce the Caries Epidemic Seattle, USA. 13-15 June 2005

Published: 10 July 2006

BMC Oral Health 2006, 6(Suppl I):SI6 doi:I0.1 186/I472-683I-6-SI-SI6

(c) 2006 Fischetti; licensee BioMed Central Ltd.

This is an open access article distributed under the terms of the Creative Commons Attribution License (http://creativecommons.org/licenses/by/2.0), which permits unrestricted use, distribution, and reproduction in any medium, provided the original work is properly cited.

\begin{abstract}
Our laboratory has developed phage lytic enzymes to prevent infection by specifically destroying disease bacteria on mucous membranes and in blood. Enzymes specific for $S$. pneumoniae and $S$. pyogenes have been developed to be used nasally and orally to control these organisms in environments such as hospitals and nursing homes to prevent or markedly reduce serious infections by these pathogens. In addition, a B. anthracis-specific enzyme was developed to kill the vegetative forms of these bacteria in the blood of infected individuals. In animal studies, $>80 \%$ of mice colonized mucosally or infected intravenously with pathogenic bacteria were decolonized or survived after a single enzyme treatment delivered to the same site of colonization or infection.
\end{abstract}

\section{Introduction}

Bacteriophages infect their host bacteria to produce more virus particles. At the end of the reproductive cycle (which may last up to an hour) they are faced with a problem, how to release the progeny phage trapped within the bacterium [1]. They solve this problem by producing an enzyme called lysin that degrades the cell wall of the infected bacteria to release the progeny phage. The lytic system consists of a holin [1] and at least one peptidoglycan hydrolase, or lysin, capable of degrading the bacterial cell wall. Lysins can be endo-beta-N-acetyl-glucosaminidases or $\mathrm{N}$-acetylmuramidases (lysozymes), which act on the sugar moiety, endopeptidases, which act on the peptide cross bridge, or more commonly, an $\mathrm{N}$-acetylmuramoyl-L-alanine amidase (or amidase), which hydrolyzes the amide bond connecting the sugar and peptide moieties. Typically, the holin is expressed in the late stages of phage infection, forming a pore in the cell membrane, allowing the preformed lysin(s) to gain access to the cell wall peptidoglycan, resulting in release of progeny phage. Significantly, exogenously added lysin can lyse the cell wall of healthy, uninfected cells, producing a phenomenon known as lysis from without. However, because of the lack of an outer membrane, this event is observed only in gram-positive bacteria.

While lysins have been known for many years [2-5], our laboratory is the first to use these enzymes therapeutically and prophylactically in vivo in their purified form to kill colonizing pathogenic bacteria on mucous membrane surfaces and in blood. We have been successful in using such enzymes to kill $S$. pyogenes [6,7] and more recently, $B$. anthracis [8]. All of these enzymes are highly evolved molecules designed for a specific purpose, to quickly destroy the bacterial cell wall, and as such, we find that nanogram to sub-microgram quantities of enzyme per milliliter is sufficient to sterilize a $10^{7}$ bacterial suspension in seconds. To date, other than chemical agents, there is 
no biological compound known that can kill bacteria this quickly. Such phage lytic enzymes are the culmination of millions of years of development by the bacteriophage and its association with bacteria. Since nearly all bacteria are or can be infected by bacteriophage, such enzymes may be developed for nearly all disease-causing bacteria. It appears, however, that these enzymes work best against gram-positive bacteria. In these organisms, the enzyme is able to rapidly access the bonds in the peptidoglycan when added extrinsically. In the gram-negative bacteria, the outer membrane is a barrier for these enzymes.

\section{Enzyme Structure}

A feature of those phage lytic enzymes that have been characterized so far is their domain structure $[9,10]$. Generally, the $\mathrm{N}$-terminal domain contains the catalytic activity of the enzyme, which will cleave one of the four major bonds in the peptidoglycan of the bacterial cell wall as described above [1]. Of the phage lytic enzymes that have been reported thus far, the great majority are amidases. The C-terminal domain of phage lytic enzymes has specificity for a cell wall substrate [11-14]. Thus, unless the binding domain binds to its wall substrate, the catalytic domain will not cleave, offering specificity to most enzymes studied. The reason for this specificity was not apparent at first, since it seemed counterintuitive that the phage would specifically design an enzyme that was lethal for its host organism. However, as we learned more about how these enzymes function, the possible reason for this specificity became apparent (see below, Resistance to Enzymes).

\section{Mode of Action}

By thin section electron microscopy of phage enzymetreated bacteria, it appears that the enzymes exert their lethal effects by digesting the peptidoglycan in localized areas, forming holes in the cell wall. Because the osmotic pressure inside a bacterium is approximately 3 atmospheres in relation to the normal external environment, this results in extrusion of the cytoplasmic membrane and, ultimately, hypotonic lysis. Since it has been found by Loessner [14] that these enzymes bind at an affinity of an immunoglobulin molecule, they are essentially oneuse enzymes and require multiple molecules to accomplish the job of digesting the cell wall. One explanation as to why these molecules have evolved in this way is that after lysis the tight binding to the wall substrate will restrict the movement of enzyme molecules, preventing lysis of potential phage hosts nearby.

\section{Targeted Killing}

An interesting feature of these enzymes is that they kill the species of bacteria from which they were produced. For instance, enzymes produced from streptococcal bacteriophage kill streptococci, and enzymes produced by pneu- mococcal bacteriophage kill pneumococci [6,7]. Specifically, the group C streptococcal lysin will kill group A streptococci efficiently and has a small effect on groups $\mathrm{C}$ and G streptococci, but has essentially no effect on normal oral streptococci. Similar results are seen with a pneumococcal-specific lysin. However in this case, the enzyme was also tested against strains of pneumococci that were resistant to penicillin, and the killing efficiency was the same. Unlike antibiotics, which are usually broad spectrum and kill many different bacteria found in the human body, some of which are beneficial, the phage enzymes only kill the disease bacteria with little to no effect on the normal human bacterial flora. Thus, phage lysins are molecules that enable targeted killing of pathogenic bacteria with little effect on the surrounding normal flora. When the group A streptococcal enzyme was tested for safety in two animal model systems, one mucosal and the other skin, in which enzyme was added to these surfaces daily for 7 days, and the tissues examined both visually and histologically, nothing unusual was observed. This was not surprising since the bonds cleaved by the phage enzymes are only found in bacteria and not human tissues. Thus, it is anticipated that these enzymes will be well tolerated in humans.

\section{In vivo Experiments}

Two in vivo animal models of mucosal colonization were developed to test the capacity for the lysins to kill organisms on these surfaces. An oral colonization model was developed for group A streptococci, and a nasal model was developed for pneumococci [6,7]. In both cases, when the animals were colonized with their respective bacteria and treated with a small amount of lysin specific for the colonizing organism, the animals were found to be free of colonizing bacteria two to five hours after lysin treatment. In the group A streptococcal experiment, animals were also swabbed 24 and 48 hours after lysin treatment. During that time most animals remained negative for streptococci, but one animal had died and two others showed positive colonies. We interpret these results to mean that the positive animals became infected during the first four days of colonization, where some organisms became intracellular. Thus, while the lysin is able to clear organisms found on the surface, it was unable to kill organisms that had initiated an infection. We ruled out the possibility that the organisms that appeared at 24 and 48 hrs did so because they became resistant to the lysin by checking them for their sensitivity to the lysin.

\section{Controling Anthrax}

Because phage enzymes are so efficient in killing pathogenic bacteria, they may be valuable tools in controlling biowarfare bacteria. To determine the feasibility of the approach, we identified a lytic enzyme from the gamma phage that is specific for Bacillus anthracis [15]. In cloning 
experiments using the gamma-phage DNA, we identified a 700 bp ORF in the phage genome encoding a $26 \mathrm{kDa}$ product very similar in size and features to a variety of Bacillus and Listeria, phage lysins. The gamma lysin, referred to as PlyG, was then purified to homogeneity by a two-step ion exchange chromatography procedure and tested for its lethal action on gamma phage sensitive bacilli. Three seconds after contact, as little as $10 \mathrm{ug}$ of PlyG mediated a 5,000-fold decrease in viable counts of a $\sim 10^{7}$ bacillus culture [8]. This lethal activity was observed in growth media, phosphate buffer, and even human blood. When the enzyme was then tested against five mutant $B$. anthracis strains and ten different virulent $B$. anthracis strains isolated worldwide, it was found to be lethal for them all. Although PlyG has no effect on $B$. anthracis spores, we discovered that the addition of the germinant L-alanine after a short heat shock of 60C resulted in the rapid germination of the spore, at which time the enzyme was rapidly lethal.

When $10^{7}$ Bacillus cereus strain RSVF (a close relative to $B$. anthracis) were administered intraperitoneally (IP) to fifteen mice, all died of rapidly fatal septicemia within four hours. When two sets of mice $(n=8$ and $n=17)$ were also challenged IP with bacilli but given $150 \mu \mathrm{g}$ and $50 \mu \mathrm{g}$ of PlyG respectively 15 minutes later by the same route, $70 \%-80 \%$ of the animals survived. We anticipate that higher doses of enzyme or multiple doses will result in nearly $100 \%$ protection. In a separate experiment, two groups of mice were given $124 \mathrm{cfu}$ of the $B$. anthracis Ames strain intravenously, and 15 minutes later one group received PlyG and the other buffer by the same route. When followed for 12 days, $90 \%$ of the enzyme treated mice survived, while only $10 \%$ of the control animals survived. Thus, we anticipate that this approach may be used in post-exposure cases of anthrax, in which individuals will be treated intravenously with PlyG to control the bacilli entering the blood after germination. This strategy could perhaps extend the window of antibiotic therapy and allow the innate immune system to clear any remaining bacilli.

\section{Resistance to Enzymes}

Repeated exposure to low concentrations of lysin to bacteria grown on agar plates did not lead to the recovery of resistant strains, nor were we able to identify resistant bacteria after several cycles of exposure to low concentrations of enzyme in liquid [7]. This may be explained by the fact that the cell wall receptor for the pneumococcal lysin is choline [16], a molecule that is necessary for pneumococcal viability. For group A streptococci, we find that polyrhamnose, a cell wall component of the bacteria, is necessary for lysin binding (Nelson and Fischetti, unpublished), and polyrhamnose has also been shown to be important for streptococcal growth. While not yet proven, it is possible that during a phage's association with bacteria over the millennia, to avoid becoming trapped inside the host cell, the binding domain of their lytic enzymes has evolved to target a unique and essential molecule in the cell wall, making resistance to these enzymes a rare event.

\section{Immune Response to Enzymes}

Because enzymes are proteins, one would anticipate an immune response to these molecules when delivered mucosally or systemically, resulting in the neutralization of the enzymatic activity. In order to test this, rabbits were hyperimmunized to the PlyG enzyme and the resulting antibodies tested in an ELISA assay. We found that in the two rabbits immunized, an antibody titer of $>25,000$ (reciprocal of the highest serum dilution yielding an OD of 1.0 in $30 \mathrm{~min}$ ) was found for both antisera. When PlyG was diluted 1:1 with undiluted (or diluted) antisera or preimmune serum and tested for its lytic activity, no difference was observed in the lytic activity in the immune or preimmune sera. Thus, antibodies do not have the capacity to inactivate the PlyG, indicating that it may be used chronically or for extended periods. This does not appear to be a feature of the PlyG lysin alone, since similar results were observed with antibodies to the Cpl-1 enzyme directed to pneumococci [17].

\section{Conclusion}

Phage enzymes have a broad application. Whenever there is a need to kill bacteria, and contact can be made with the organism, phage enzymes may be freely utilized. They may be used not only to control pathogenic bacteria on human mucous membranes, but may find utility in the food industry to control disease bacteria. Because of the serious problems of resistant bacteria in hospitals, day care centers, and nursing homes, particularly staphylococci and pneumococci, such enzymes may be of immediate benefit in these environments. Thus, we may add phage enzymes to our armamentarium against pathogenic bacteria. They are molecules that have been in development for millions of years by bacteriophage in their battle to survive within bacteria. They have yet to be exploited.

\section{Competing interests}

The author(s) declare that they have no competing interests.

\section{Acknowledgements}

I wish to acknowledge the members of my laboratory who are responsible for much of the work I described in this review, Qi Chang, Mattias Collin, Jutta Loeffler, Daniel Nelson, Raymond Schuch, and Pauline Yoong, and with the excellent technical assistance of Ryann Russell, Mary Windels, and Shiwei Zhu. Supported by grants from the Defense Advanced Research Project Agency (DARPA). 


\section{References}

I. Young R: Bacteriophage lysis: mechanism and regulation. Microbiol Rev 1992, 56:430-481.

2. Fischetti VA, Gotschlich EC, Bernheimer AW: Purification and physical properties of group C streptococcal phage-associated lysin. J Exp Med I 97I, I 33: I 105-I II 17.

3. Garcia P, Lopez R, Ronda C, Garcia E, Tomasz A: Mechanism of phage-induced lysis in pneumococci. J Gen Microbiol 1983, 1 29:479-487.

4. Fischetti VA, Zabriskie JB, Gotschlich EC: Physical, chemical and biological properties of Type 6 M-protein extracted with purified streptococcal phage-associated lysin. Str Dis \& Commun 1972, 317:26-36.

5. Sable S, Lortal S: The lysins of bacteriophages infecting lactic acid bacteria. Appl Microbiol Biotechnol 1995, 43:I-6.

6. Nelson D, Loomis L, Fischetti VA: Prevention and elimination of upper respiratory colonization of mice by group A streptococci by using a bacteriophage lytic enzyme. Proc Nat Acad Sci USA 200I, 98:4I07-4II2.

7. Loeffler JM, Nelson D, Fischetti VA: Rapid killing of Streptococcus pneumoniae with a bacteriophage cell wall hydrolase. Science 200I, 94:2170-2172.

8. Schuch R, Nelson D, Fischetti VA: A bacteriolytic agent that detects and kills Bacillus anthracis. Nature 2002, 4 I 8(6900):884-889.

9. Diaz E, Lopez R, Garcia JL: Chimeric phage-bacterial enzymes: a clue to the modular evolution of genes. Proc Natl Acad Sci USA $1990,87: 8125-8129$.

10. Garcia P, Garcia JL, Sanchez-Puelles JM, Lopez R: Modular organization of the lytic enzymes of Streptococcus pneumoniae and its bacteriophages. Gene 1990, 86:81-88.

II. Lopez R, Garcia E, Garcia P, Garcia JL: The pneumococcal cell wall degrading enzymes: a modular design to create new lysins? Microb Drug Resist 1997, 3:199-2II.

12. Lopez R, Garcia J, Garcia E, Ronda C, Garcia P: Structural analysis and biological significance of the cell wall lytic enzymes of Streptococcus pneumoniae and its bacteriophage. FEMS Microbiol Lett 1992, 79:439-447.

13. Garcia E, Garcia JL, Arraras A, Sanchez-Puelles JM, Lopez R: Molecular evolution of lytic enzymes of Streptococcus pneumoniae and its bacteriophages. Proc Natl Acad Sci USA 1988, 85:9|4-9|8.

14. Loessner MJ, Kramer K, Ebel F, Scherer S: C-terminal domains of Listeria monocytogenes bacteriophage murein hydrolases determine specific recognition and high-affinity binding to bacterial cell wall carbohydrates. Mol Microbiol 2002, 44:335-349.

15. Watanabe T, Morimoto A, Shiomi T: The fine structure and the protein composition of gamma phage of Bacillus anthracis. Can J Microbiol 1975, 21:1889-1892.

16. Garcia P, Garcia E, Ronda C, Tomasz A, Lopez R: Inhibition of lysis by antibody against phage-associated lysin and requirement of choline residues in the cell wall for progeny phage release in Stretococcus pneumoniae. Curr Microbiol 1983, 8:137-140.

17. Loeffler JM, Djurkovic S, Fischetti VA: Phage lytic enzyme Cpl-I as a novel antimicrobial for pneumococcal bacteremia. Infect Immun 2003, 71:6199-6204.

Publish with Bio Med Central and every scientist can read your work free of charge

"BioMed Central will be the most significant development for disseminating the results of biomedical research in our lifetime. "

Sir Paul Nurse, Cancer Research UK

Your research papers will be:

- available free of charge to the entire biomedical community

- peer reviewed and published immediately upon acceptance

- cited in PubMed and archived on PubMed Central

- yours - you keep the copyright
BioMedcentral 